\title{
Development and Substantiation of a RP-HPLC Method for Monitoring of Impurities in Pirfenidone Drug Substance
}

\author{
Suresh Babu Bodempudi1,2, Ravichandra Babur ${ }^{1 *}$, Konda Srinivasa Reddy ${ }^{3}$ \\ ${ }^{1}$ Dr. Konda's Life Sciences Private Limited, Hyderabad, India \\ ${ }^{2}$ Department of Analytical Chemistry, Gitam Institute of Sciences, Gitam University, Visakhapatnam, India \\ ${ }^{3}$ Brundavan Laboratories Private Limited, Nalgonda, India \\ Email: *rrcbabu7@yahoo.in,b_sureshmsc2000@yahoo.co.in
}

Received 23 October 2015; accepted 12 December 2015; published 15 December 2015

Copyright (C) 2015 by authors and Scientific Research Publishing Inc.

This work is licensed under the Creative Commons Attribution International License (CC BY).

http://creativecommons.org/licenses/by/4.0/

c) (†) Open Access

\section{Abstract}

A simple, rapid and rugged RP-HPLC method was developed for evaluation and quantification of impurities present in Pirfenidone (PFD) drug substance. Impurities were separated and determined on a Zorbax RX-C18 column $(250 \mathrm{~mm}$ length, $4.6 \mathrm{~mm}$ inner diameter and $5.0 \mu \mathrm{m}$ particle size, octadecylsilane chemically bonded to porous silica) with $0.02 \mathrm{M} \mathrm{KH}_{2} \mathrm{PO}_{4}$ buffer and acetonitrile as mobile phase using a simple gradientelution program. The column flow rate of $1.0 \mathrm{~mL}$ per minute was used for the separation. The detection wave length was fixed at $220 \mathrm{~nm}$. The method was substantiated with respect to specificity, precision, linearity, range, accuracy, ruggedness, limit of detection and quantitation. The impurities were identified as 2-hydroxy-5-methylpyridine and Iodobenzene. The linearity range obtained was 0.017 to $0.380 \mu \mathrm{g} / \mathrm{mL}$ for 2 -hydroxy-5-methylpyridine, 0.047 to $0.382 \mu \mathrm{g} / \mathrm{mL}$ for Pirfenidone and 0.030 to $0.99 \mu \mathrm{g} / \mathrm{mL}$ for Iodobenzene with the retention times of $3.248 \mathrm{~min}, 10.608 \mathrm{~min}$ and $24.241 \mathrm{~min}$ for 2-hydroxy-5-methylpyridine, Pirfenidone and Iodobenzene, respectively. The percentage recoveries of 2-hydroxy-5-methylpyridine and Iodobenzene were in the range of $94.08 \%-104.12 \%$. The LOD and LOQ values were found $0.000005 \mathrm{mg} / \mathrm{mL}, 0.000017 \mathrm{mg} / \mathrm{mL}$ for 2 -hydroxy-5-methylpyridine and $0.009 \mu \mathrm{g} / \mathrm{mL}, 0.030$ $\mu \mathrm{g} / \mathrm{mL}$ for Iodobenzene, respectively. The method is found to be suitable for the quantitation of impurities along with Pirfenidone drug substance. The method was validated as per the International Conference on Harmonization (ICH) guidelines.

\section{Keywords}

Development, Validation, Pirfenidone, Degradation, Quantification and RP-HPLC

\footnotetext{
${ }^{*}$ Corresponding author.
}

How to cite this paper: Bodempudi, S.B., Babur, R. and Reddy, K.S. (2015) Development and Substantiation of a RP-HPLC Method for Monitoring of Impurities in Pirfenidone Drug Substance. American Journal of Analytical Chemistry, 6, 10191029. http://dx.doi.org/10.4236/ajac.2015.613097 


\section{Introduction}

Pirfenidone (PFD) is a novel antifibrotic agent approved for mild to moderate Idiopathic pulmonary fibrosis (IPF) as orphan drug. Idiopathic pulmonary fibrosis (IPF) is a progressively fibrotic disease, with no effective treatment and a median survival time of 2 - 5 years. IPF inevitably causes shortness of breath and destruction of healthy lung tissue, although some people may experience periods of stability with the disease [1] [2]. IPF is a rare incurable disease, often fatal which mostly affects geriatric patients causing fibrosing interstitial pneumonia of unknown etiology [3]. Pirfenidone is a small non-peptide molecule of low molecular weight (185.2 daltons) with the chemical name of 5-methyl-1-phenyl-2-(1H)-pyridone. A survey of literature revealed that LC-MS/MS [4] and HPLC [5]-[7] methods are reported for the determination of Pirfenidone in biological fluids [8]. Hence, an attempt has been made to develop an accurate, rapid, specific and reproducible method for determination of Pirfenidone and all two impurities in bulk drug samples and in pharmaceutical dosage forms along with method validation as per ICH norms [9] [10]. The stability tests were also performed on drug substances as per ICH norms. No methods have been reported in literature and in pharmacopoeia for the estimation of Pirfenidone and its process related impurities in pharmaceutical drug substance form. Hence, the present work is taken up to develop and validate the method for the determination of PFD and its related impurities (Figures 1(a)-(c)) in drug substance form. In the present paper we describe an excellent reversed phase high performance liquid chromatography (RP-HPLC) method for the separation, determination and quantification of process related impurities of Pirfenidone.

\section{Experimental}

\subsection{Instrumentation}

The LC system used for the method development and validation consisted of a dual piston reciprocating two Waters pumps from Waters alliance, USA (model HPLCe2695) and photo-diode array detector from Waters Crop., USA (model 2998). The HPLC system was equipped with data acquisition and processing software "Empower-2” Waters Crop., USA. Agilent Zorbax RX-C18 column (250 mm × 4.6 mm I.D., $5 \mu$ particle size) was used.

\subsection{Chemicals and Solvents}

Samples of Pirfenidone and its two impurities [the key starting materials used for the synthesis of Pirfenidone is 2-hydroxy 5-methyl bromide and Iodobenzene. During the synthesis process of pirfedone drug substance there is every possibility that the above may be invariably carry in to API. As per ICH guidelines it should be less than 0.1\%] namely 2-hydroxy-5-methylpyridine and Iodobenzene were synthesized from Dr. Konda's life sciences, Hyderabad, India. The working standards of 2-hydroxy-5-methyl pyridine 99.9\%, Pirfenidone 99.7\% and Iodobenzene $99.9 \%$ were provided as gift samples by Dr. Konda’s Life sciences private limited, Hyderabad, India. $\mathrm{KH}_{2} \mathrm{PO}_{4}$ 99.8\% and HPLC grade acetonitrile 99.9\%, Milli-Q water, $\mathrm{H}_{3} \mathrm{PO}_{4} 85.0 \%$ (AR grade) were purchased from Merck Ltd, Mumbai, India.

\subsection{Mobile Phase Preparation}

Weigh and transfer about $2.7 \mathrm{~g}$ of Potassium dihydrogen phosphate in $1000 \mathrm{~mL}$ of Milli-Q water and sonicate to<smiles>Cc1ccc(=O)n(-c2ccccc2)c1</smiles>

(a)<smiles>Cc1ccc(=O)[nH]c1</smiles>

(b)<smiles>Ic1ccccc1</smiles>

(c)

Figure 1. (a) Chemical structure of Pirfenidone; (b) Chemical structure of 2-hydroxy-5-methyl pyridine; (c) Chemical structure of Iodobenzene. 
dissolve. Adjust the $\mathrm{pH}$ to 2.5 ( \pm 0.05 ) using dilute Orthophosphoric acid. Filter through 0.45 -micron porosity membrane and degas. Acetonitrile used as mobile phase Band diluents as blank solution.

\subsection{Diluent Preparation}

Buffer and acetonitrile were mixed in the ratio of $40: 60 \mathrm{v} / \mathrm{v}$ to prepare diluent.

\subsection{Standard Solution Preparation}

The standard solutions were prepared by weighing accurately each $10 \mathrm{mg}$ of 2-hydroxy-5-methyl pyridine, Pirfenidone and Iodobenzene [working standards] and transferred into three $100 \mathrm{~mL}$ volumetric flask to dissolved and diluted to the mark with diluent. Further diluted $1 \mathrm{~mL}$ of the above solutions to $100 \mathrm{~mL}$ with diluent. Further diluted $2.5 \mathrm{~mL}$ of this solution to $10 \mathrm{~mL}$ with diluent to obtain the concentrations of $0.25 \mu \mathrm{g} / \mathrm{mL}$ of 2-hydroxy5-methyl pyridine, Pirfenidone and Iodobenzene.

\subsection{Sample Solution Preparation}

Weighed and transferred accurately $25 \mathrm{mg}$ of Pirfenidone drug substance into a $50 \mathrm{~mL}$ volumetric flask, dissolved and diluted to the volume with diluent to produce the concentrations of $0.5 \mathrm{mg} / \mathrm{mL}$ of Pirfenidone.

\subsection{Chromatographic Conditions}

The chromatographic separation was achieved on Zorbax RX-C18, $25 \mathrm{~cm} \times 4.6 \mathrm{~mm}, 5 \mu \mathrm{m}$ column using a mobile phase containing mixture of $\mathrm{KH}_{2} \mathrm{PO}_{4}$ buffer $\left(\mathrm{pH} 2.5\right.$ with $\mathrm{H}_{3} \mathrm{PO}_{4}$ ) and Acetonitrile as mobile phase. The mobile phase was filtered through nylon membrane (pore size $0.45 \mu \mathrm{m}$ ). The flow rate of the mobile phase was $1.0 \mathrm{~mL} / \mathrm{min}$. The column temperature was maintained at $25^{\circ} \mathrm{C}$ and the wavelength was monitored at $220 \mathrm{~nm}$. The injection volume was $10 \mu \mathrm{L}$ and the run time was 50 minutes by using with simple gradient method.

\subsection{Procedure}

Solutions of Pirfenidone $(0.5 \mathrm{mg} / \mathrm{mL})$ and its two impurities $(0.25 \mu \mathrm{g} / \mathrm{mL})$ were prepared in diluent. A $20 \mu \mathrm{L}$ volume of each solution injected and chromatographed under the above conditions. The system suitability was determined by injecting $0.25 \mu \mathrm{g} / \mathrm{mL}$ solution of 2-hydroxy-5-methyl pyridine and Iodobenzene were spiked with Pirfenidone $(0.5 \mathrm{mg} / \mathrm{mL})$ and evaluated by making five replicate injections. The system was deemed to be suitable for use if the resolution was greater than 1.5 or higher and column for all the components in matrix. Standard solutions and samplesolutions were analysed the above same conditions. The content of impurity was calculated from the peak area.

\section{Method Development and Method Validation}

\subsection{Method Development}

To develop a suitable and robust RP-HPLC method for the simultaneous estimation of Pirfenidone and its related impurities in different mobile phases were employed to achieve the best separation and resolution.

The method development was made with Zorbax RX-C 18 (250 $\mathrm{mm} \times 4.6 \mathrm{~mm}$ I.D., $5 \mu$ particlesize $)$. Detection was carried out at $220 \mathrm{~nm}$ with the mobile phase composed $0.02 \mathrm{M} \mathrm{KH}_{2} \mathrm{PO}_{4}$ buffer $\mathrm{pH} 2.5$ with $\mathrm{H}_{3} \mathrm{PO}_{4}$ and Acetonitrile in the ratio of $65: 35 \mathrm{v} / \mathrm{v}$ at a flow rate of $1.0 \mathrm{~mL} / \mathrm{min}$ was used for the separation.

\subsection{Validation of Method}

\subsubsection{Specificity}

Specificity is the ability of the method to measure the analyte response in the presence of its potential impurities. The specificity of the developed LC method for Pirfenidone was carried out in the presence of its impurities namely 2-hydroxy-5-methyl pyridine and Iodobenzene. Stress studies were performed for Pirfenidone bulk drug to provide an indication of the stability indicating property and specificity of the proposed method. The following sample solutions were prepared and injected into chromatographic system to demonstrate the analytical method is selective for determination of related substances in Pirfenidone. Prepared and injected individual sample 
solutions of 2-hydroxy-5-methylpyridine, Pirfenidone and Iodobenzene in diluent. Prepared a spiked sample solution by spiking of 2-hydroxy-5-methylpyridine and Iodobenzene impurity in Pirfenidone sample solution. Specificity chromatogram and results were shown in Figure 2 and Table 1.

\subsubsection{System Suitability}

The standard solution was prepared and analysed as per the proposed method, calculated the \% RSD for peak area of Pirfenidone and each specified impurity in standard solution and the \% RSD for peak area of Pirfenidone and each specified impurity throughout the run injections to demonstrate system suitability for studying of each validation parameter. System suitability parameter values were shown in Table 2.

\subsubsection{Precision}

The precision of the related substance method was checked by injecting ten individual preparations of Pirfenidone $(0.5 \mathrm{mg} / \mathrm{mL})$ spiked with $0.25 \mu \mathrm{g} / \mathrm{mL}$ of 2-hydroxy-5-methyl pyridine and Iodobenzene with respect to Pirfenidone drug substance concentration. The \% Relative Standard Deviation of area for each 2-hydroxy-5methyl pyridine and Iodobenzene was calculated.

The intermediate precision of the method was also evaluated by using different analyst, different column and different instrument in the same laboratory. Results of system precision studies are shown in Table 3. To study the method precision, six replicate mixed sample solutions of 2-Hydroxy-5-methyl pyridine, Pirfenidone and Iodobenzene were injected. The percent relative standard deviation (\% RSD) was calculated. Results of method precision studies were shown in Table 4.

\subsubsection{Accuracy}

The accuracy study of the impurities was carried out by standard spiking method. A known amount of standard solution was added to the permanent amount of pre-analyzed sample solution. Standard spiking method was executed at three plus one concentration levels of 50\%, 100\%, 120\% and 150\%. Recovery studies for 2-hydroxy5-methyl pyridine and Iodobenzene results were shown in Table 5.

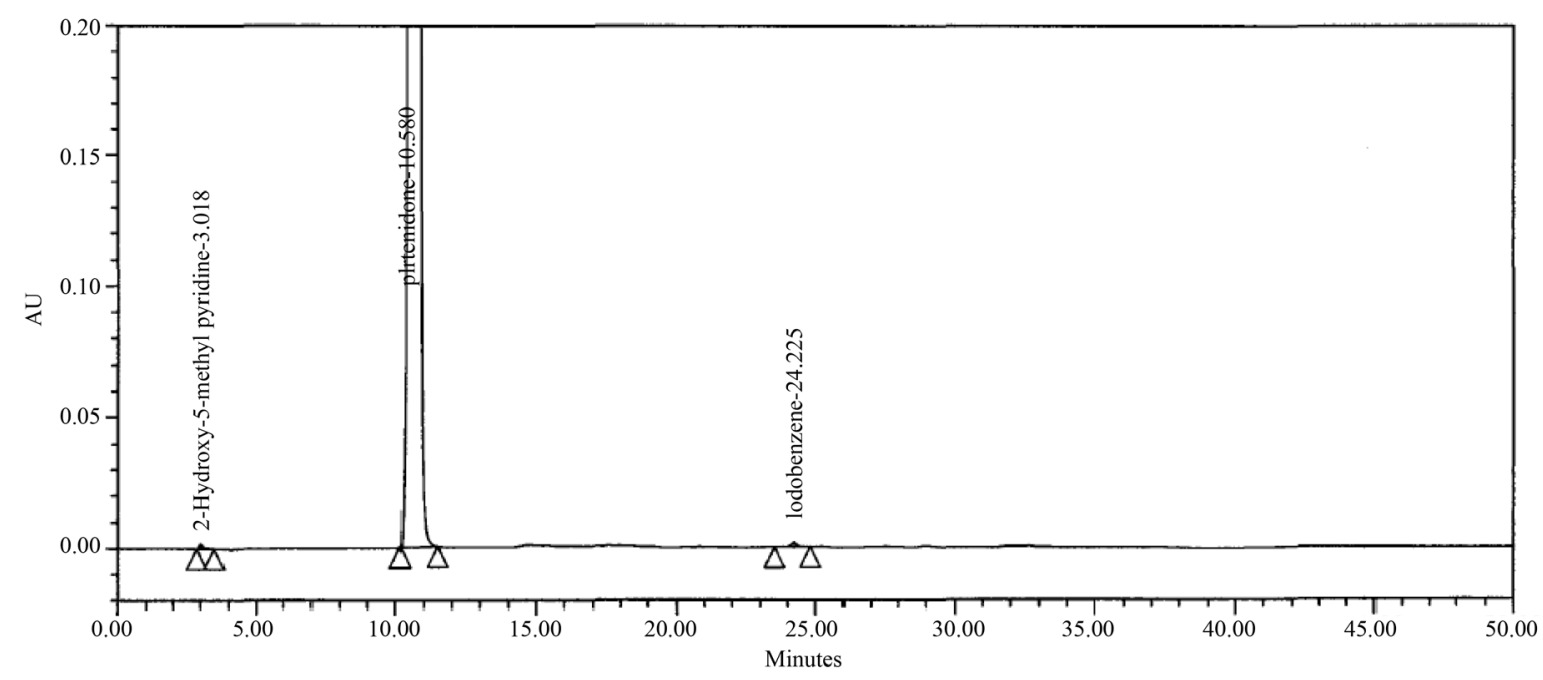

Figure 2. Typical chromatogram of specificity.

Table 1. Peak purity and resolution results.

\begin{tabular}{|c|c|c|c|c|c|c|c|c|}
\hline & Name & RT & Area & $\%$ Area & $\begin{array}{c}\text { Purity1 } \\
\text { threshold }\end{array}$ & $\begin{array}{l}\text { Purity1 } \\
\text { angle }\end{array}$ & RT ratio & Resolution \\
\hline 1 & $\begin{array}{c}\text { 2-hydroxy-5-methyl } \\
\text { pyridine }\end{array}$ & 3.25 & 3796 & 0.11 & 4.272 & 3.713 & 0.31 & ---- \\
\hline 2 & Pirfenidone & 10.60 & 3,526,715 & 99.79 & 1.011 & 0.037 & 1.00 & 19.54 \\
\hline 3 & Iodobenzene & 24.24 & 3725 & 0.11 & 8.054 & 4.249 & 2.29 & 33.31 \\
\hline
\end{tabular}


Table 2. System suitability parameter for 2-hydroxy-5-methyl pyridine, Pirfenidone and Iodobenzene. (a) Summary of the percentage relative standard deviation of peak area of each specified impurity and Pirfenidone in four replicate injections of standard solution in each validation parameter; (b) Summary of the percentage relative standard deviation of peak area of each specified impurity and Pirfenidone in throughout the run injections of standard solution in each validation parameter.

(a)

\begin{tabular}{cccc}
\hline \multirow{2}{*}{ Validation parameter } & \multicolumn{2}{c}{ \% RSD of peak area in standard solution for four replicate injections (NMT 5.0\%) } \\
\cline { 2 - 4 } Specificity & 2-hydroxy-5-methylpyridine & Pirfenidone & Iodobenzene \\
\hline $\begin{array}{c}\text { Determination of LOD \& LOQ } \\
\text { values }\end{array}$ & 0.71 & 1.52 & 0.98 \\
Precision at LOQ & 1.44 & 1.77 & 2.14 \\
Linearity study & 1.87 & 0.98 & 1.37 \\
Accuracy & 2.08 & 1.78 & 0.65 \\
System precision & 0.91 & 1.22 & 2.18 \\
Method precision & 2.10 & 0.48 & 3.01 \\
Intermediate precision & 0.45 & 1.72 & 2.05 \\
Robustness study-actual & 1.50 & 1.78 & 1.36 \\
\hline
\end{tabular}

(b)

\begin{tabular}{cccc}
\hline \multirow{2}{*}{ Validation parameter } & \multicolumn{2}{c}{ \% RSD of peak area in standard solution for five replicate injections (NMT 5.0\%) } \\
\cline { 2 - 3 } $\begin{array}{c}\text { Specificity } \\
\text { Determination of LOD \& LOQ }\end{array}$ 2-hydroxy-5-methylpyridine & Pirfenidone & Iodobenzene \\
values & 1.84 & 1.54 & 0.85 \\
Precision at LOQ & 0.80 & 1.62 & 1.80 \\
Linearity study & 1.28 & 1.31 & 1.93 \\
Accuracy & 1.62 & 2.11 & 1.20 \\
System precision & 1.80 & 1.11 & 0.56 \\
Method precision & 1.94 & 0.81 & 2.26 \\
Intermediate precision & 1.91 & 1.54 & 2.99 \\
Robustness study-actual & 0.52 & 2.92 & 1.83 \\
\hline
\end{tabular}

Table 3. System precision for 2-hydroxy-5-methyl pyridine, Pirfenidone and Iodobenzene.

\begin{tabular}{|c|c|c|c|}
\hline Injection No. & 2-hydroxy-5-methylpyridine & Pirfenidone & Iodobenzene \\
\hline 1 & 25,874 & 17,170 & 23,610 \\
\hline 2 & 26,236 & 17,267 & 22,915 \\
\hline 3 & 25,895 & 17,230 & 22,410 \\
\hline 4 & 26,338 & 17,077 & 22,809 \\
\hline 5 & 25,932 & 16,759 & 22,934 \\
\hline 6 & 24,648 & 17,129 & 21,867 \\
\hline 7 & 26,081 & 17,079 & 22,387 \\
\hline 8 & 26,342 & 17,132 & 22,011 \\
\hline 9 & 26,346 & 17,155 & 22,421 \\
\hline 10 & 25,814 & 17,121 & 22,894 \\
\hline Average peak area & 25,951 & 17,112 & 22,626 \\
\hline SD & 503.6315 & 137.7820 & 511.2144 \\
\hline$\%$ RSD & 1.94 & 0.81 & 2.26 \\
\hline
\end{tabular}


Table 4. Method precision for 2-hydroxy-5-methyl pyridine, Pirfenidone and Iodobenzene.

\begin{tabular}{ccccc}
\hline $\begin{array}{c}\text { Preparation No. } \\
\text { (spiked sample) }\end{array}$ & $\begin{array}{c}\text { 2-hydroxy-5-methylpyridine } \\
(\% \mathrm{w} / \mathrm{w})\end{array}$ & $\begin{array}{c}\text { Iodobenzene } \\
(\% \mathrm{w} / \mathrm{w})\end{array}$ & $\begin{array}{c}\text { Single maximum } \\
\text { impurity }(\% \mathrm{w} / \mathrm{w})\end{array}$ & $\begin{array}{c}\text { Total impurities } \\
(\% \mathrm{w} / \mathrm{w})\end{array}$ \\
\hline 1 & 0.047 & 0.045 & 0.013 & 0.105 \\
2 & 0.046 & 0.046 & 0.013 & 0.105 \\
3 & 0.044 & 0.041 & 0.013 & 0.098 \\
4 & 0.042 & 0.044 & 0.014 & 0.100 \\
5 & 0.046 & 0.044 & 0.014 & 0.104 \\
6 & 0.043 & 0.046 & 0.011 & 0.102 \\
Average (\% w/w) & 0.045 & 0.044 & 0.013 & 0.0030 \\
SD & 0.0020 & 0.0019 & 0.0011 & 2.97 \\
\hline
\end{tabular}

Table 5. Recovery studies for 2-hydroxy-5-methyl pyridine and Iodobenzene.

\begin{tabular}{ccc}
\hline \% level & $\begin{array}{c}\text { \% mean recovery of 2-hydroxy-5-methyl } \\
\text { pyridine }\end{array}$ & \% mean recovery of Iodobenzene \\
\hline 50 & 102.89 & 96.85 \\
100 & 95.13 & 100.79 \\
120 & 94.08 & 101.64 \\
150 & 99.74 & 104.12 \\
\hline
\end{tabular}

\subsubsection{Linearity}

Linearity test solutions for the related substance method were prepared by diluting stock solutions to the required concentrations. The solutions were prepared at six concentration levels of 2-Hydroxy-5-methyl pyridine, Pirfenidone and Iodobenzene from LOQ to $150 \%(0.25 \mathrm{\mu g} / \mathrm{mL})$ of the specification level (LOQ, $25 \%, 50 \%$, $75 \%, 100 \%, 125 \%$ and $150 \%)$. i.e., 0.017 to $0.380 \mu \mathrm{g} / \mathrm{mL}$ for 2 -Hydroxy-5-methyl pyridine, 0.047 to 0.382 $\mu \mathrm{g} / \mathrm{mL}$ for Pirfenidone 0.030 to $0.379 \mu \mathrm{g} / \mathrm{mL}$ for Iodobenzene respectively. Twenty micro liters of each concentration was injected in duplicate into the HPLC system. From these chromatograms, the mean peak areas were calculated and linearity plots of concentration over the mean peak areas were constructed individually. The \% R.S.D. value of the slope and Y-intercept of the calibration curve was calculated. The correlation coefficient should be not less than 0.99. Linearity plots are shown in Figures 3-5. Linearity results were shown in Table 6.

\subsubsection{Limit of Detection and Limit of Quantification}

The LOD and LOQ for 2-hydroxy-5-methyl pyridine, Pirfenidone and Iodobenzene were determined at a signalto-noise ratio of 3:1 and 10:1, respectively, by injecting a series of dilute solutions with known concentrations. Precision study was also carried out at the LOQ level by injecting six individual preparations 2-hydroxy-5methyl pyridine, Pirfenidone and Iodobenzene and calculating the \% Relative standard deviation of the area. The LOD and LOQ values of 2-hydroxy-5-methyl pyridine, Pirfenidone and Iodobenzene were given in Table 7 and LOD chromatograms were shown in Figure 6 and in Figure 7.

\subsubsection{Robustness}

The robustness of an analytical method is a gauge of its ability to stay unchanged by little, but deliberate variations in method parameter and provides a sign of its dependability throughout normal usage. The robustness was performed in different flow rate $1.0 \mathrm{~mL} / \mathrm{min} \pm 0.2 \mathrm{~mL} / \mathrm{min}$, different $\mathrm{pH}$ of Mobile phase $2.5 \pm 0.2$, Buffer strength $0.02 \pm 0.05 \mathrm{M}$, Injection volume $20 \mu \mathrm{L} \pm 10 \mu \mathrm{L}$ and Gradient program solvent strength $65 \% \pm 2 \%$. Relative standard deviation was observed for all impurities with Pirfenidone are similar in all changed condition in 0.05\% impurities spiked with Pirfenidone. The consequences of robustness study are presented in Table 8. 


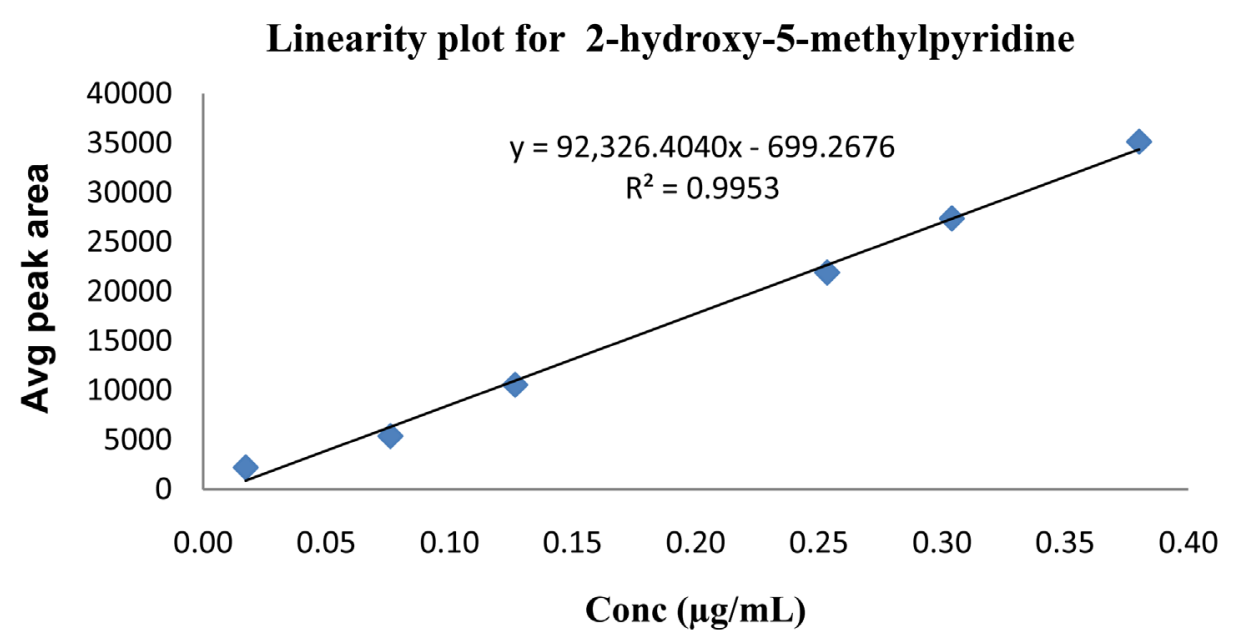

Figure 3. Linearity plot for 2-hydroxy-5-methyl pyridine.

\section{Linearity plot for Pirfenidone}

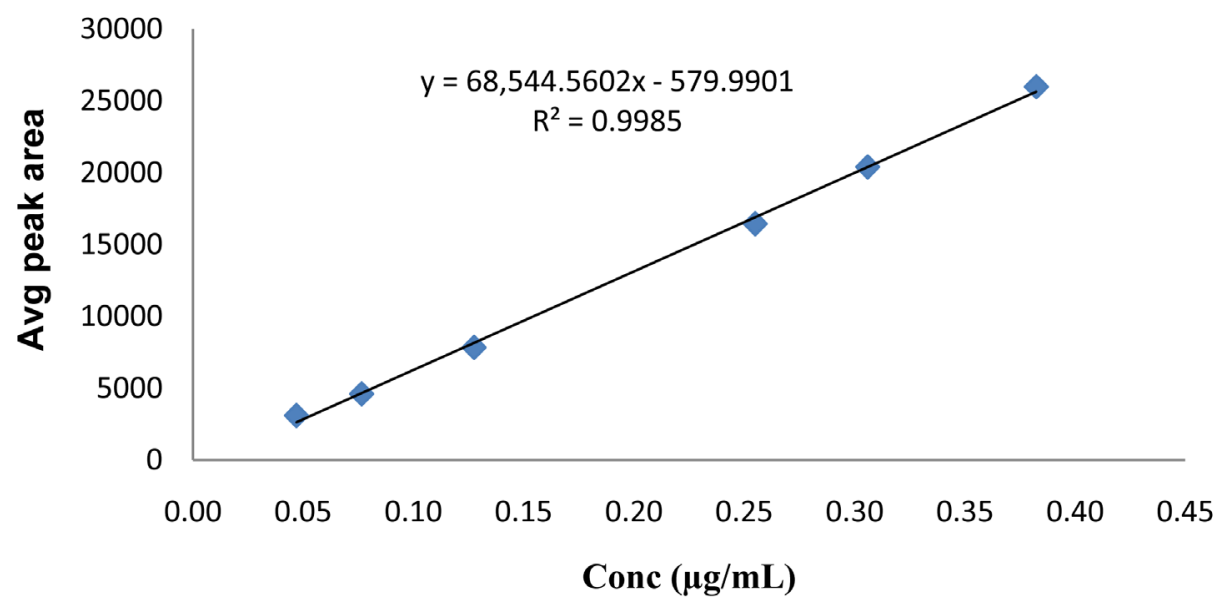

Figure 4. Linearity plot for Pirfenidone.

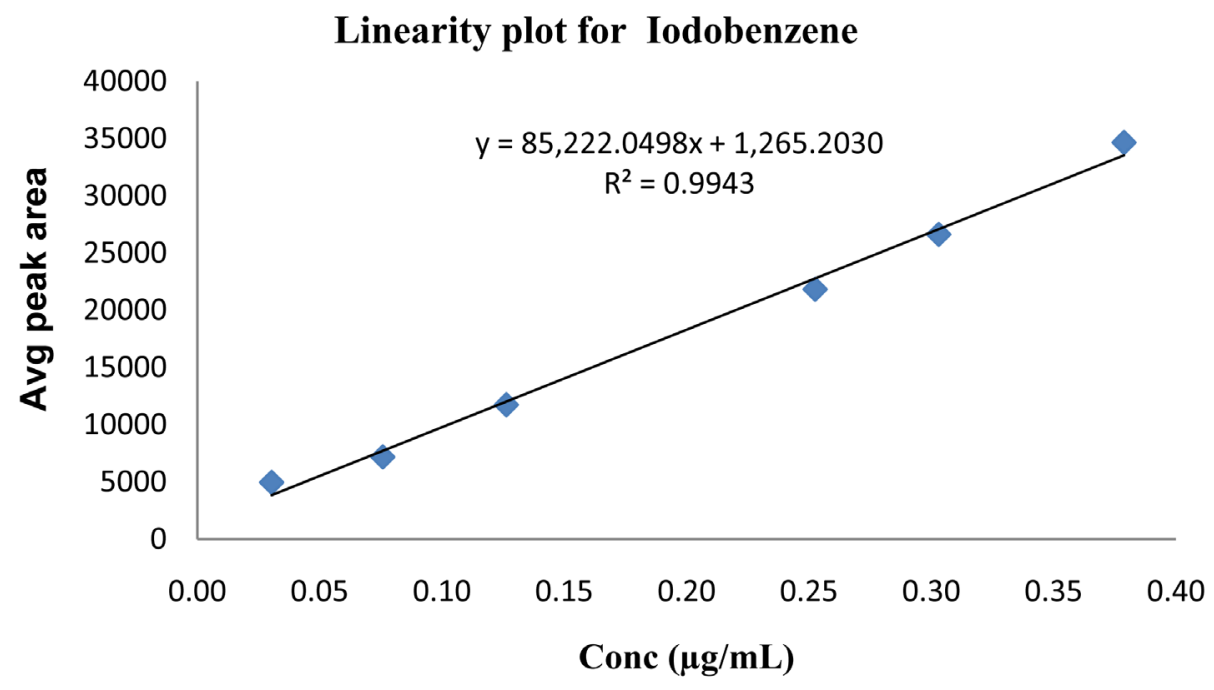

Figure 5. Linearity plot for Iodobenzene. 


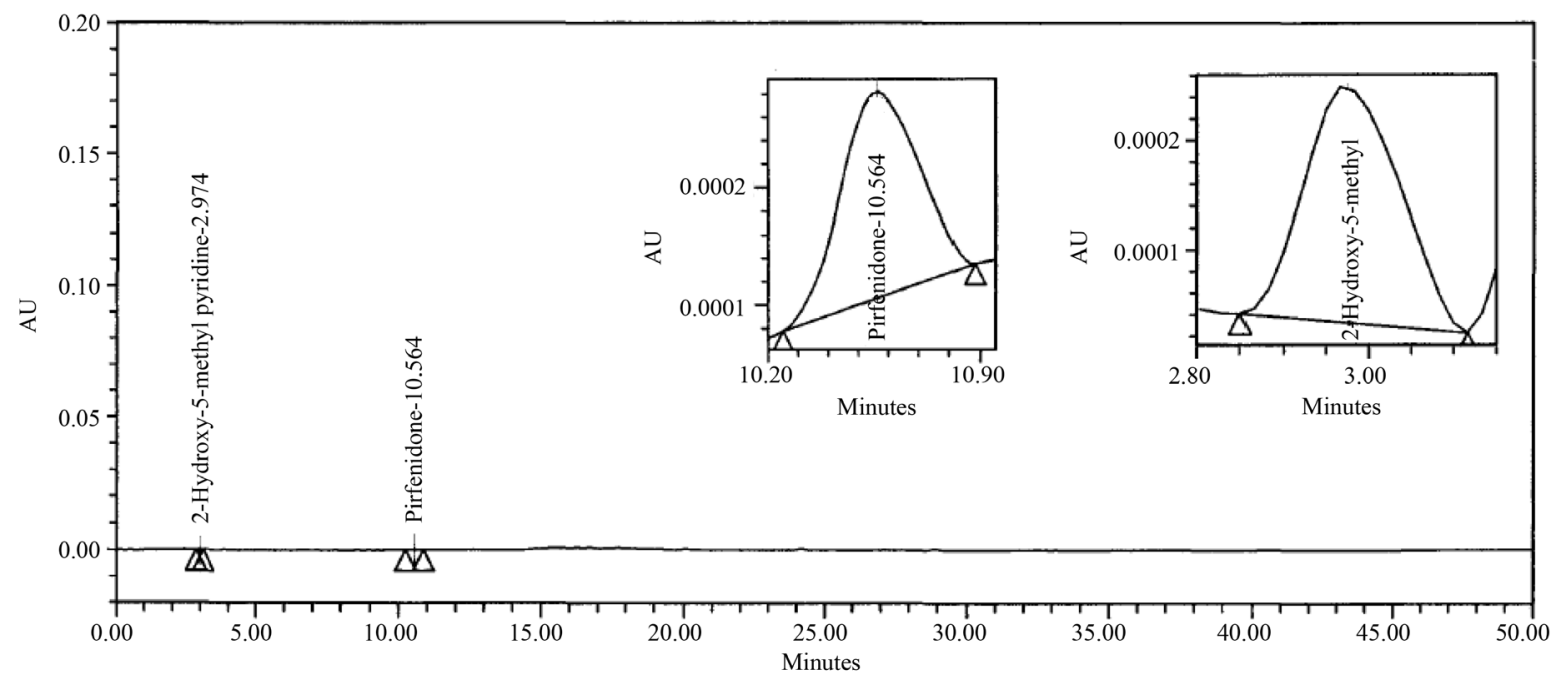

Figure 6. Typical LOQ chromatogram for 2-hydroxy-5-methyl pyridine and Pirfenidone.

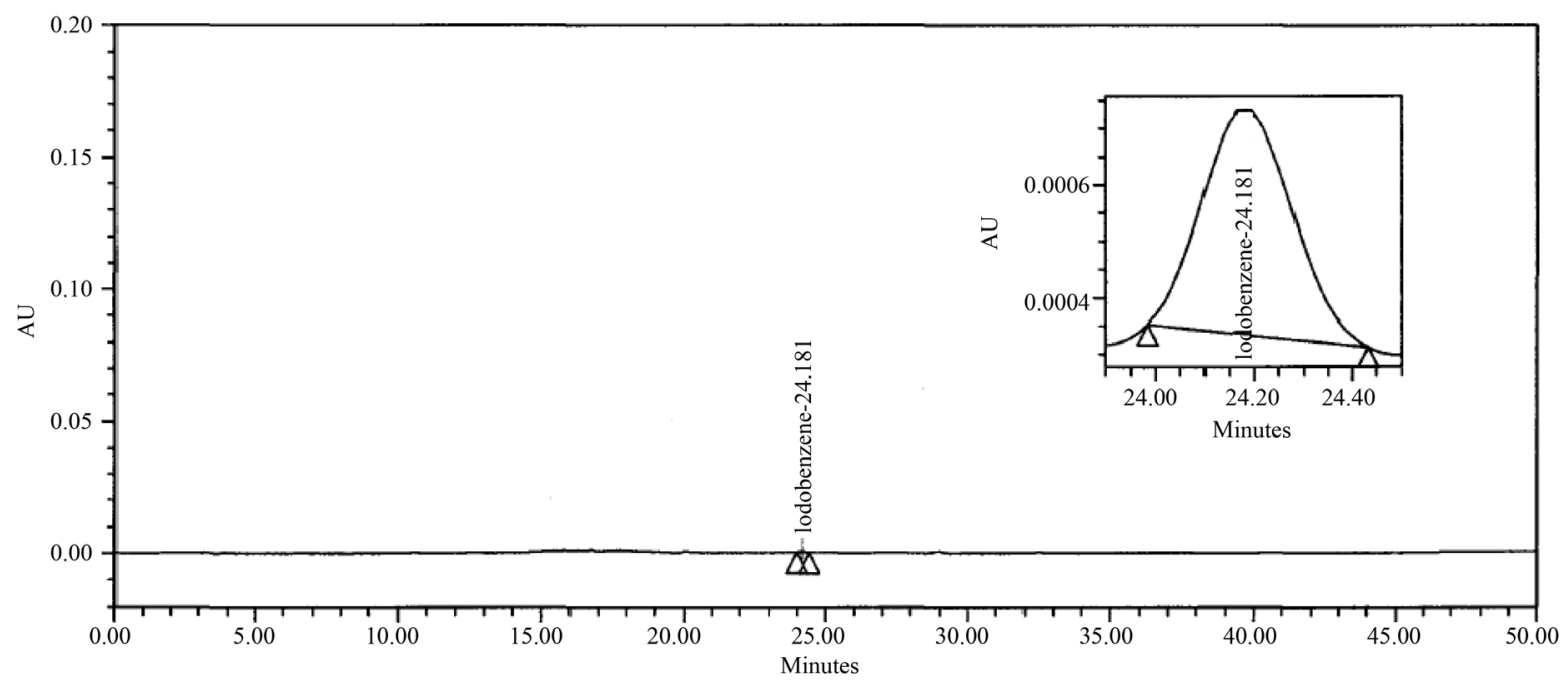

Figure 7. Typical LOQ chromatogram for Iodobenzene.

Table 6. Linearity of 2-hydroxy-5-methyl pyridine, Pirfenidone and Iodobenzene.

\begin{tabular}{|c|c|c|c|c|c|c|}
\hline \multirow{2}{*}{$\begin{array}{l}\text { S. } \\
\text { No. }\end{array}$} & \multicolumn{2}{|c|}{ 2-hydroxy-5-methyl pyridine } & \multicolumn{2}{|c|}{ Pirfenidone } & \multicolumn{2}{|c|}{ Iodobenzene } \\
\hline & $\begin{array}{l}\text { Concentration } \\
(\mathrm{mg} / \mathrm{ml})\end{array}$ & Mean peak area & $\begin{array}{l}\text { Concentration } \\
(\mathrm{mg} / \mathrm{ml})\end{array}$ & Mean peak area & $\begin{array}{l}\text { Concentration } \\
(\mathrm{mg} / \mathrm{ml})\end{array}$ & Mean peak area \\
\hline 1 & 0.000017 & 2228 & 0.000047 & 3099 & 0.000030 & 4960 \\
\hline 2 & 0.000076 & 5392 & 0.000076 & 4605 & 0.000076 & 7191 \\
\hline 3 & 0.000127 & 10,572 & 0.000127 & 7838 & 0.000126 & 11,738 \\
\hline 4 & 0.000253 & 21,925 & 0.000255 & 16,447 & 0.000253 & 21,835 \\
\hline 5 & 0.000304 & 27,385 & 0.000306 & 20,401 & 0.000303 & 26,625 \\
\hline 6 & 0.000380 & 35,152 & 0.000382 & 25,985 & 0.000379 & 34,658 \\
\hline
\end{tabular}


Table 7. LOD and LOQ for 2-hydroxy-5-methyl pyridine, Pirfenidone and Iodobenzene.

\begin{tabular}{ccccc}
\hline S. No & Parameter & 2-hydroxy-5-methyl pyridine & Pirfenidone & Iodobenzene \\
\hline 1 & LOD (\%) & $0.001(0.005 \mu \mathrm{g} / \mathrm{mL})$ & $0.003(0.014 \mu \mathrm{g} / \mathrm{mL})$ & $0.002(0.009 \mu \mathrm{g} / \mathrm{mL})$ \\
2 & LOQ (\%) & $0.005(3.4 \mu \mathrm{g} / \mathrm{mL})$ & $0.01(9.4 \mu \mathrm{g} / \mathrm{mL})$ & $0.01(6.0 \mu \mathrm{g} / \mathrm{mL})$ \\
\hline
\end{tabular}

Table 8. Robustness for 2-hydroxy-5-methyl pyridine, Pirfenidone and Iodobenzene.

\begin{tabular}{cccc}
\hline Parameter & 2-hydroxy-5-methyl pyridine & Pirfenidone & Iodobenzene \\
\hline $0.8 \mathrm{ml} / \mathrm{min}$ & 2.24 & 1.75 & 0.95 \\
$1.0 \mathrm{ml} / \mathrm{min}$ & 1.50 & 1.24 & 1.36 \\
$1.2 \mathrm{ml} / \mathrm{min}$ & 1.96 & 1.68 & 0.5 \\
$\mathrm{pH} 2.3$ & 0.67 & 1.51 & 0.82 \\
$\mathrm{pH} 2.5$ & 1.50 & 1.24 & 1.36 \\
$\mathrm{pH} 2.7$ & 3.80 & 1.32 & 2.48 \\
Buffer strength $0.015 \mathrm{M}$ & 1.68 & 3.16 & 1.54 \\
Buffer strength $0.020 \mathrm{M}$ & 1.50 & 1.24 & 1.36 \\
Buffer strength $0.025 \mathrm{M}$ & 0.43 & 1.55 & 3.95 \\
Injection volume $10 \mu \mathrm{L}$ & 1.00 & 2.18 & 1.36 \\
Injection volume $20 \mu \mathrm{L}$ & 1.50 & 1.24 & 0.82 \\
Injection volume $30 \mu \mathrm{L}$ & 2.66 & 1.89 & 0.93 \\
Gradient program $63: 37 \mathrm{v} / \mathrm{v}$ & 0.50 & 3.38 & 1.36 \\
Gradient program $65: 35 \mathrm{v} / \mathrm{v}$ & 1.50 & 1.24 & 1.55 \\
Gradient program $73: 33 \mathrm{v} / \mathrm{v}$ & 0.84 & 2.07 & \\
\hline
\end{tabular}

\subsubsection{Ruggedness}

The related substances analysis was performed in different instrument, different column, different analyst and different dates. The results of ruggedness study are given in Table 9.

\subsection{Stability}

The stability of the drug in solution during analysis was determined by analysis of samples in the $0.1 \mathrm{~N}$ sodium hydroxide and acetonitrile was evaluated by analyzing solutions were spiked with impurities at specification level. The solutions were tested after 24 hours at room temperature and the results established that the samples were constant at these circumstances. Simultaneously the solution of Pirfenidone in the $0.1 \mathrm{~N}$ Hydrochloric acid and Acetonitrile was stored for 24 hours and analysed on the next day. No significant change was observed with the chromatogram. The total amount of impurities was found to be a maximum of $0.04 \%$ in the sample. The described method is satisfactory toobtain accurate and consistent values for the determination of related substances in Pirfenidone drugsubstance. From these results it could be seen that the developed method was simple and useful for monitoring of potential impurities of Pirfenidone drug substance. The results of stability study are given in Table 10.

\section{Results and Discussion}

The main objective of the Analytical method is to separate Pirfenidone from 2-hydroxy-5-methyl pyridine and Iodobenzene. Impurities were not separated properly and peak shapes were not good by using different stationary phases such as C8, and different mobile phases. The Chromatographic separation was achieved on a Zorbax RX C18 (250 $\mathrm{mm} \times 4.6 \mathrm{~mm}$ I.D., $5 \mu$ particle size $)$, flow rate of $1.0 \mathrm{~mL} / \mathrm{min}$. 
Table 9. Ruggedness for 2-hydroxy-5-methyl pyridine, Pirfenidone and Iodobenzene.

\begin{tabular}{ccccc}
\hline Ruggedness & $\begin{array}{c}\text { 2-hydroxy-5-methylpyridine } \\
\text { (\% RSD) }\end{array}$ & $\begin{array}{c}\text { Iodobenzene } \\
\text { (\% RSD) }\end{array}$ & $\begin{array}{c}\text { Single maximum } \\
\text { impurity (\% RSD) }\end{array}$ & $\begin{array}{c}\text { Total impurities } \\
\text { (\% RSD) }\end{array}$ \\
\hline Analyst-1 & 4.44 & 4.32 & 8.46 & 2.97 \\
Analyst-2 & 0.00 & 1.00 & 3.33 & 0.35 \\
\hline
\end{tabular}

Table 10. Stability data for Pirfenidone and its related substances.

\begin{tabular}{cccccc}
\hline Stability condition & $\begin{array}{c}\text { Purity } \\
\text { (area\%) }\end{array}$ & $\begin{array}{c}\text { 2-hydroxy-5-methylpyridine } \\
\text { (area\%) }\end{array}$ & $\begin{array}{c}\text { Iodobenzene } \\
\text { (area\%) }\end{array}$ & $\begin{array}{c}\text { Single maximum } \\
\text { impurity (area\%) }\end{array}$ & $\begin{array}{c}\text { Total } \\
\text { impurities } \\
\text { (area\%) }\end{array}$ \\
\hline $\begin{array}{c}\text { Pirfenidone @ } \\
\text { N N HCl-RT after } 24 \\
\text { hours }\end{array}$ & 99.91 & ND & ND & 0.01 & 0.09 \\
$\begin{array}{c}\text { Pirfenidone @ } \\
\text { N N NaH-RT 24 hours }\end{array}$ & 99.90 & ND & ND & 0.03 & 0.07 \\
\hline
\end{tabular}

In preliminary experiments all the impurities and Pirfenidone were subjected to RP-HPLC on Inertsil- $\mathrm{C}_{18}$ column with Ammonium acetate buffer $(0.05 \mathrm{M})$ and Methanol as solvents. Peak shapes were not good when mobile phase used as diluent. In another attempt, Water:Acetonitrile:Triflouro acetic acid (50:50:0.10 v/v) have been tried and the chromatogram was recorded. Peak shapes as well as separation were not good. Finally the mobile phase was replaced with $0.02 \mathrm{M} \mathrm{KH}_{2} \mathrm{PO}_{4}$ buffer, $\mathrm{pH} 2.5$ with $\mathrm{H}_{3} \mathrm{PO}_{4}$ and Acetonitrile in the ratio of 65:35 v/v. Good separation and quantification was achieved with simple gradient program. The sample injection volume was $10 \mu \mathrm{l}$. Detection was carried out at $220 \mathrm{~nm}$ and chromatographic run time was $50 \mathrm{~min}$. A typical chromatogram of a mixture of impurities along with Pirfenidone shown in Figure 1. The peaks were identified by injecting and comparing with the retention times of the individual compounds. The order of elution was 2-hydroxy-5-methyl pyridine, Pirfenidone and Iodobenzene. The method was substantiated with respect to the Specificity, precision (System precision, Method precision and Intermediate precision), accuracy, linearity, limit of detection Limit of Quantitation, Precision at Limit of Quantitation, Robustness and Solution stability.

The retention times for 2-hydroxy-5-methyl pyridine, Pirfenidone and Iodobenzene was found to be 3.25, 10.60 and 24.24 min respectively and the peak shapes were good. The results of system suitability parameters indicate good performance and hence the method is specific. For system precision study, the \% Relative Standard Deviation was found to be 1.94, 0.81 and 2.26 for 2-hydroxy-5-methyl pyridine, Pirfenidone and Iodobenzene respectively, which are well within the acceptable criteria of not more than $4.0 \%$ for ten standard injections. For method precision study, the \% Relative Standard Deviation was found to be 4.44, 4.32, 8.46 and 2.97 for 2-hydroxy-5-methyl pyridine, Iodobenzene, single maximum impurity and Total impurities respectively, which are well within the acceptable criteria of not more than $10.0 \%$ for six spiked samples. This reveals that the method is quite precise.

In method precision, the percentage RSD for the each specified impurity and total impurities (Pirfenidone spiked with each specified impurity at $100.0 \%$ level) obtained was in the range of $2.97 \%$ to $8.46 \%$ at the working concentration, The percentage relative standard deviation for the each specified impurity [Pirfenidone spiked sample prepared six times (intermediate precision) at the specification level] are in the range of $0.00 \%$ to $1.00 \%$ at the working concentration.

The percentage relative standard deviation for the single maximum unspecified impurity and total impurities [Pirfenidone spiked sample prepared six times (intermediate precision) at the specification level] are in the range of $0.36 \%$ to $3.33 \%$ at the working concentration. This indicates that the analytical method was robust and rugged.

\section{Conclusion}

A simple, specific, linear, accurate and precise normal phase HPLC method was successfully developed, which was capable of separating the two impurities from Pirfenidone. The developed and validated method can be used for the related substances testing of Pirfenidone. The developed method is also stable and can be used for the quantitative determination of related substances in bulk materials. 


\section{References}

[1] Ministry of Health, Labor and Welfare (2008) Report on Deliberation Results. Nonproprietary Name: Pirfenidone Evaluation and Licensing Division, Pharmaceutical and Food Safety Bureau. http://www.pmda.go

[2] (2010) CHMP Assessment Report. International Nonproprietary Name: Pirfenidone Procedure No. EMEA/H/C/002154. European Medicines Agency. http://www.ema.europa.eu

[3] Raghu, G., Collard, H.R., Egan, J.J., Martinez, F.J., Behr, J., Brown, K.K., et al. (2011) An Official ATS/ERS/JRS/ ALAT Statement: Idiopathic Pulmonary Fibrosis: Evidence-Based Guidelines for Diagnosis and Management. American Journal of Respiratory and Critical Care Medicine, 183, 788-824. http://dx.doi.org/10.1164/rccm.2009-040GL

[4] Tong, S., Wang, X., Jiang, H., Xuegu, X., Pan, Y., Kunming, C., et al. (2010) Determination of Pirfenidone in Rat Plasma by LC-MS-MS and Its Application to a Pharmacokinetic Study. Chromatographia, 71, 709-713. http://dx.doi.org/10.1365/s10337-010-1538-5

[5] Shi, S., Wu, J., Shi, S., Wu, J. and Zeng, F. (2008) Development and Validation of an Improved LC Method for the Simultaneous Determination of Pirfenidone and Its Carboxylic Acid Metabolite in Human Plasma. Chromatographia, 69, 459-463. http://dx.doi.org/10.1365/s10337-008-0910-1

[6] Wang, Y., Zhao, X., Zhong, J., Chen, Y., Liu, X. and Wang, G. (2006) Simple Determination of Pirfenidone in Rat Plasma via High-Performance Liquid Chromatography. Biomedical Chromatography, 20, 1375-1379. http://dx.doi.org/10.1002/bmc.708

[7] Tamilselvi, N. and Krurian, D.S. (2012) Bioanalytical Method Development and Validation of Pirfenidone by RPHPLC Method and Its Application to the Determination of Drug Food Interaction Study in Wister Rats. International Journal of Pharmaceutical and Biomedical Research, 3, 132-142.

[8] (2005) International Conference on Harmonization. Guidance on Validation of Analytical Procedure: Text and Methodology. ICH-Q2 (R1). IFPMA, Geneva.

[9] ICH Stability (2003) Testing of New Drug Substances and Products Q1A (R2). International Conference on Harmonization, IFPMA, Geneva.

[10] ICH Photo Stability (1996) Testing of New Drug Substances and Products Q1b. International Conference on Harmonization, IFPMA, Geneva.

\section{Abbreviations}

ICH: international conference on harmonization mm: milli meter nm: nano meter $\mu$ : micron $\mu \mathrm{L}$ : micro litre $\mathrm{mL}$ : millilitre $\%$ : percent RSD: relative standard deviation v/v: volume/volume LOD: limit of detection LOQ: limit of quantitation min: minute $\mathrm{N}$ : normality AR: analytical reagent mg: milli gram 